\title{
Evidence for an abstract lexical representation of word structure
}

\author{
MARCUS TAFT \\ University of New South Wales, Kensington, New South Wales, Australia
}

\begin{abstract}
Subjects were required to judge whether a particular visually presented word was a homophone or not. When instructed not to read the word aloud, subjects had difficulty with words whose orthography suggested a morphological structure different from that suggested by their homophones, for example, FINED (homophonic with FIND). There were no major problems encountered when the two members of the homophonic pair had the same morphological structure, for example, KNEAD. When subjects were instructed to read the word aloud before making a decision, however, their performance on the morphologically different items improved markedly. This result suggests, first, that inflected words are represented in the lexicon as stem plus affix and, second, that silent reading involves a more abstract phonological representation than the actual phonetic representation produced by reading aloud.
\end{abstract}

The experiments reported in this paper addressed the issue of the lexical representation of word structure. "Word structure" refers to the morphology, orthography, and pronunciation of a word. It is generally assumed that access to the lexical entry for a word makes available information about the sound of the word and the spelling of the word (e.g., Morton, 1980; Rubenstein, 1974; Seidenberg \& Tanenhaus, 1979), and it has also been demonstrated that the morphological structure of a word is somehow expressed in the lexical representation (e.g., Gibson \& Guinet, 1971; Taft, 1979; Taft \& Forster, 1975).

Although it is often supposed that information about pronunciation and spelling becomes available or is activated once a lexical entry has been accessed, little attention has been paid to the nature of this information. It seems to be generally assumed that orthography and pronunciation are represented in a form similar to that in which they manifest themselves when overtly produced. Henderson (1982), however, suggested an alternative to this assumption by centering on the well-developed linguistic notion of a morphophonemic lexical representation (N. Chomsky \& Halle, 1968). Henderson suggested that there is one abstract representation that incorporates morphological structure and from which both pronunciation and orthography can be derived.

The morphophonemic level of representation is one in which words that are morphemically related have the same abstract phonemic representation even though the actual phonetic realizations of their common stem may be quite different. For example, the words TELEGRAPH and TELEGRAPHY are morphemically related, but the

This work was supported by a grant from the Australian Research Grants Scheme. The author's mailing address is: School of Psychology, University of New South Wales, Kensington, New South Wales 2033, Australia. pronunciations of the two common morphemes TELE and GRAPH are quite different (as in [t $\dot{\varepsilon}] \partial$ græf] and [təlégraf $\mathrm{l}:]$ ). At the morphophonemic level, however, the words are represented with the same underlying structure \#te 1Egraf\#. ${ }^{1}$ There are rules that convert this underlying representation in to the correct pronunciation, the particular realization depending upon whether or not the suffix $-Y$ is present. Thus, pronunciation is derived from the morphophonemic representation by rule application.

Orthography can also be derived from the underlying representation, but in a more direct way, because the morphophonemic representation often is reflected in the orthography of a word (C. Chomsky, 1973; N. Chomsky \& Halle, 1968). For example, the spelling of TELEGRAPH and TELEGRAPHY reflects the morphemic relationship between these words rather than their phonetic dissimilarity. Similarly, the word SIGN is spelled with a $G$ because there is a $/ g$ / in the underlying representation, reflecting the word's relationship to SIGNIFY, in which the $G$ is pronounced. In order to spell a word correctly, however, one often needs more information than simply the morphophonemic representation. For example, nothing in the underlying representation for ISLAND would lead one to spell it with an $S$, since there are no morphologically related words in which the $S$ is realized phonetically. Similarly, the underlying representation for KNEE provides no information indicating that $/ \mathrm{n}$ / should be spelled as $K N$ and / $t: /$ as EE (rather than as EA). Thus, in a number of cases, there needs to be access to specific orthographic information.

If the morphophonemic description of lexical representation is correct, then words that are pronounced in exactly the same way but that have different lexical representations will exist in the lexicon. Consider the homophonic words FIND and FINED. The underlying representations for these two words differ in that the 
former is \#find\#, whereas the latter is \#fin \#d. Similarly, the homophones LAX and LACKS are rep. resented as \#læks\# and \#lak\#s, respectively. Most homophonic pairs, however, have identical morphophonemic representations. For example, both HEELED and HEALED are represented as \#hël\#d, and both NEED and KNEAD are represented as \#nēd\#.

In Experiment 1, a task in which subjects were asked to say whether or not a visually presented word was a homophone was employed. The subjects were asked not to say the words aloud. It was thought that such a task might possibly be performed by using the lexical representations of the words, rather than their surface pronunciations. If this were so, and if the lexical representation were morphophonemic, then it should have been difficult for the subjects to detect that FIND was homophonic with FINED and that LACKS was homophonic with LAX, whereas it should have been relatively easy to detect that HEALED was homophonic with HEELED and NEED with KNEAD. This was tested in Experiment 1 .

\section{EXPERIMENT 1}

\section{Method}

Subjects. Ten undergraduate and graduate students participated in the experiment. They were tested individually.

Materials. Four different conditions were examined, with 16 words in each condition. All of these words were homophonic with another, higher frequency English word (frequency was determined from the norms of Carroll, Davies, \& Richman, 1971).

In Conditions 1 and 2, each word had a morphophonemic structure different from that of the word with which it was homophonic. The words presented in Condition 1 were all inflected, for example, FINED (homophonic with FIND), COWERED (homophonic with COWARD), and BREWS (homophonic with BRUISE); those presented in Condition 2 were all uninflected, for example, LAX (homophonic with LACKS), MIST (homophonic with MISSED), and HIRE (homophonic with HIGHER).

In Conditions 3 and 4 , each word had the same morphophonemic structure as that of the word with which it was homophonic. The words presented in Condition 3 were all inflected, for example, HEELED (homophonic with HEALED), MANORS (homophonic with MANNERS), and REIGNED (homophonic with RAINED); those presented in Condition 4 were all uninflected, for example, KNEAD (homophonic with NEED), SLEIGH (homophonic with SLAY), and CARAT (homophonic with CARROT).

These 64 homophonic items (listed in the Appendix) were presented in uppercase, randomly mixed with 32 nonhomophonic words that were either inflected (e.g., GNAWED) or uninflected (e.g., ACHE).

Procedure. Words appeared in list form. They were presented visually in one of three different orders to the subjects. The subjects were instructed that they could repeat the words to themselves but should not say them aloud. For each word, they were to respond "yes" or "no," depending upon whether or not there was another English word that could be pronounced in exactly the same way but that was spelled differently. The example of SALE and SAIL was used. The subjects were not put under time pressure to respond.

\section{Results}

The percentage of occasions that a "yes" response was correctly made is given in Table 1 .

An analysis of these data revealed that Condition 1 differed significantly from the other three conditions [Condition 1 vs. Condition $2, \min \mathrm{F}^{\prime}(1,36)=6.92$, $\mathrm{p}<.02$; Condition 1 vs. Condition $3, \min \mathrm{F}^{\prime}(1,38)=$ $32.05, \mathrm{p}<.001$; Condition 1 vs. Condition $4, \min \mathrm{F}^{\prime}$ $(1,37)=40.64, p<.001]$. In addition, Condition 2 was associated with significantly more errors than were both Condition $3\left[\min \mathrm{F}^{\prime}(1,38)=6.82, \mathrm{p}<.02\right]$ and Condition $4\left[\min F^{\prime}(1,37)=14.31, p<.001\right]$. The dif ference between Conditions 3 and 4 was not significant [min $\left.F^{\prime}(1,37)=1.44\right]$, although the analysis of the subject means did reach significance $\left[F_{1}(1,9)=11.29, p<\right.$ $\left..01 ; F_{2}(1,30)=1.65, p>.05\right]$.

The false-alarm rate for the nonhomophonic items was very low, being $1.88 \%$ (i.e., 3 errors, of a possible 160) for both the inflected items (e.g., GNAWED) and the uninflected items (e.g., ACHE).

\section{Discussion}

The data reveal that homophones with different morphological structures, such as FINED/FIND and LAX/ LACKS, are more difficult to recognize as homophones than are those with the same morphological structure, such as HEELED/HEALED and KNEAD/NEED. This implies, first, that inflected words have structured lexical representations different from those of uninflected words (as previously has been supported by Gibson \& Guinet, 1971, Jarvella \& Meijers, 1983, Stanners, Neiser, Hernon, \& Hall, 1979, and Taft, 1979), and, second, that these different morphological structures are reflected in the difficulty subjects have in making a decision about the pronunciation of a word. Such a result is consistent with the view that lexical representations are morphophonemic in nature.

One finding that was not predicted by the morphophonemic account, however, was the Condition 1 words would produce more errors than Condition 2 words. That is, when the presented word was morphophonemically different from its homophonic pair, the ability to recognize its homophony was weaker when it was an in flected word (e.g., FINED) than when it was an unin flected word (e.g., LAX). By the morphophonemic ac-

Table 1

Percentage Correct Responses for the Four Conditions in Experiment 1 (Silent Reading)

\begin{tabular}{cllc}
\hline Condition & $\begin{array}{c}\text { Example } \\
\text { of Item }\end{array}$ & $\begin{array}{c}\text { Correct } \\
\text { Response to } \\
\text { Example }\end{array}$ & $\begin{array}{c}\text { Percent } \\
\text { Correct }\end{array}$ \\
\hline 1 & Fined & Find & 28 \\
2 & Lax & Lacks & 54 \\
3 & Heeled & Healed & 78 \\
4 & Knead & Need & 88 \\
\hline
\end{tabular}


count, difficulty in recognizing homophony should result from a mismatch of lexical representations; the directionality of that mismatch should not be relevant.

An explanation for the difference between Conditions 1 and 2 might lie with the actual items used. Condition 1 included a number of words whose homophony with another word depended on a syllable containing the letter $\mathrm{R}$ being pronounced / $/$ /. For example, PATTED is homophonic with PATTERED in the Australian dialect because the ER of the latter word is reduced to $/ \%$. Other examples are STRETCHES/STRETCHERS, COWARD/COWERED, and HUMOURED/HUMID. No such items appeared in Condition 2. It was noticeable that these items in Condition 1 were especially difficultthey had a mean detection rate of only $14 \%$ (there were seven such items). It is possible that it was the presence of these items in Condition 1 that led to more errors in this condition than in Condition 2 . In fact, a comparison of the nine remaining items in Condition 1 with the items in Condition 2 reveals no difference $[t(23)=1.53$, $\mathrm{p}>.1]$.

Why should these seven items have been particularly difficult? One possible answer lies in the fact that the difference between the morphophonemic representations of the two members of these homophonic pairs is more marked than that between the other types. The morphophonemic representations of homophonic pairs such as FINED and FIND are less structurally different (i.e., \#fīn\#d vs. \#find\#) than are those like PATTERED and PATTED (i.e., \#pætər\#放 and \#pæt\#d). The members of the latter pair differ in the actual number of morphophonemes in their representations.

At this stage, however, rather than offering alternative theoretical explanations for the findings, an obvious and trivial explanation must first be discounted. This is the question of whether pairs like PATTERED and PATTED (and even LAX and LACKS) are in fact genuinely homophonic. Certainly, American and British readers might be skeptical about the homophony in Australian dialect of such pairs as PATTED and PATTERED, given that these are clearly not homophonic in their own dialects. Experiment 2 was set up with this criticism in mind, although the experiment had theoretical significance as well.

In Experiment 1, it was thought that the homophone decision might be performed at an abstract level, in that subjects were not receiving any overt phonetic input, in particular, overt phonetic input generated by the subjects themselves. If, on the other hand, subjects did receive self-generated phonetic input, it is likely that the homophone decision would then be performed at the phonetic level, with only minimal morphophonemic influences coming into play from the abstract level. If this were so, then subjects should be able to make their homophone decisions equally well across all four conditions when they are instructed to read the presented words aloud. If this were the case, then any questions regarding the homophony of the items would be resolved.
In addition, any criticisms concerning such factors as the frequencies of the homophonic words (which were not well matched across conditions) would also be circumvented, in that the only difference between Experiments 1 and 2 was whether or not the subjects said the word aloud. The words used in Experiment 2 remained the same as those in Experiment 1.

\section{EXPERIMENT 2}

\section{Method}

The materials and procedure were exactly the same as those in Experiment 1, except that subjects were instructed to read the words aloud and to try to base their decisions on their selfgenerated utterances. Ten students who had not participated in Experiment 1 were used as subjects.

\section{Results}

Table 2 provides the percentage of times that the homophone decision was correctly made.

In a series of planned comparisons, only one comparison came close to being significant, namely, Condition 1 vs. Condition $4\left[\mathrm{~min} \mathrm{~F}^{\prime}(1,36)=3.57, \mathrm{p}>.05\right]$, with both the subject analysis $\left[\mathrm{F}_{1}(1,9)=10.29, \mathrm{p}<.02\right]$ and item analysis $\left[F_{2}(1,30)=5.46, p<.05\right]$ reaching significance.

The false-alarm rate was again extremely low, being $0.625 \%$ (i.e., 1 error, of a possible 160 ) for the inflected items and $0 \%$ for the uninflected items.

Comparison of Experiment 1 (silent reading) with Experiment 2 (overt pronunciation) revealed that there was a significant improvement in both Condition 1 and Condition 2 when the words were spoken aloud $\left[\min F^{\prime}(1,30)\right.$ $=28.53, \mathrm{p}<.001$, and $\min \mathrm{F}^{\prime}(1,26)=9.63, \mathrm{p}<.01$, re spectively $]$. On the other hand, there was no improvement in performance in Conditions 3 and $4\left(\min F^{\prime}<1\right.$ in both cases). In other words, it appeared that performance in Conditions 3 and 4 was already about as good as it could be in the silent task, whereas performance in Conditions 1 and 2 was deficient in the silent task relative to that in the overt-pronunciation task.

\section{Discussion}

The fact that Condition 1 did not differ from Conditions 2 and 3 (and possibly from Condition 4) indicates that the words used in Condition 1 were considered to be just as homophonic as those used in the other condi-

Table 2

Percentage Correct Responses for the Four Conditions in Experiment 2 (Overt Pronunciation)

\begin{tabular}{cllc}
\hline Condition & $\begin{array}{c}\text { Example } \\
\text { of Item }\end{array}$ & $\begin{array}{c}\text { Correct } \\
\text { Response to } \\
\text { Example }\end{array}$ & $\begin{array}{c}\text { Percent } \\
\text { Correct }\end{array}$ \\
\hline 1 & Fined & Find & 76 \\
2 & Lax & Lacks & 79 \\
3 & Heeled & Healed & 81 \\
4 & Knead & Need & 91 \\
\hline
\end{tabular}


tions. The fact that the percentage of correct responses to the seven particularly dubious items whose homophony depended on the reduction to / $/ 2$ of a syllable containing an $\mathrm{R}$ improved from 14\% correct in Experiment 1 to 69\% in Experiment 2 indicates that at least the majority of the subjects definitely considered these words to be homophones.

The marked difference for Conditions 1 and 2 between the silent-reading and the overt-pronunciation tasks is interesting. It implies that subvocal feedback is different from vocal feedback and, in particular, that subvocalization is performed at a more abstract level than is overt vocalization. So far, I have described this abstract level in terms of morphophonemes as envisaged by N. Chomsky and Halle (1968). However, this is not the only possibility.

One alternative is a spelling-based phonological representation that is an amalgamation of orthography and phonology. Ehri (1980) and Ehri and Wilce (1980) supported such a view. For example, the orthographically based representation of the pronunciation of PITCH includes a $/ t /$, whereas the representation of RICH does not (Ehri \& Wilce, 1980). One formalization of what Ehri suggests might be something like the morphophonemic representation of N. Chomsky and Halle (1968), but with an added orthographic influence. By this account, the abstract representation for ISLAND would include an $/ \mathrm{s} /$ even though $\mathrm{S}$ is never manifest in any words morphologically related to ISLAND. The notion that orthography can influence the abstract underlying phonemic representation has been also advocated in the linguistic literature (e.g., Kerek, 1976). The difficulty observed with Condition 1 and 2 words can be explained in the same way that the pure morphophonemic account explains it. However, a problem arises with Condition 3 and 4 words. The abstract representation, for example, of KNEAD would be different from that of NEED, since the $K$ would be represented. How do subjects decide so easily that these are homophonic?

One possible answer to this might be that subjects have access to information about what letters can be pronounced in the same way. That is, perhaps they use something like the grapheme-to-grapheme conversion rules proposed by Taft (1982). Taft found that subjects often thought that a nonword like MUSKLE was homophonic with MUSCLE but that RUSKLE was not homophonic with RUSTLE. This suggested that subjects have access to information which says that $C$ and $K$ can be pronounced in the same way and, further, that this information is employed when making a decision about homophony. Although the notion of grapheme-grapheme rules was originally postulated as an alternative to prelexical grapheme-phoneme rules and not as an alternative to any lexical generation of phonology, it is possible to adapt it for this latter purpose. That is, there could be morphophoneme-morphophoneme conversion rules (M-M rules). If one restricts the range of M-M conversion to morphophonemes that fall within the same word boundaries (symbolized by \#), then there will be a rule that converts $/ \mathrm{kn} /$ to $/ \mathrm{n} /$, but no rule that converts $/ \varepsilon \mathrm{d} / \mathrm{to}_{\mathrm{O}} / \mathrm{d} /$ (as in \#finn\# $\mathrm{d}$ and \#find\#), since $/ \varepsilon \mathrm{d} /$ and $/ d /$ are never pronounced in the same way within the same word boundary. Similarly, there would be no rule converting / $\varepsilon r /$ to $/ /$ as in \#pæt $\varepsilon \mathrm{r} \# \varepsilon \mathrm{d}$ and \#pæt\#\&d, for the same reason.

This orthographically influenced morphophonemic account (which I will term the morphographemic account) is not quite the same as a purely orthographic account. A purely orthographic account is one that says that pronunciation is developed by spelling-to-sound rules from an orthographic lexical representation and not from any direct lexical representation of the phonology. The crucial difference between a morphographemic representation and an orthographic representation is that the former represents morphemic structure, whereas the latter does not. If one modifies the orthographic representation to include morphemic structure, for example, PATTER\#ED, then the representation becomes essentially morphographemic: / $/ \mathbf{x} /$ is simply represented as $\mathrm{A}$, and $/ \mathrm{t} / \mathrm{as} \mathrm{TT}$. The morphographemic explanation of the homophonedecision results entails the use of grapheme-grapheme conversion rules that have been modified by morphemic considerations. The purely orthographic account runs into problems here. Why should grapheme-grapheme rules be modified by morphemic structure if the lexical representation does not include morphemic structure?

Another argument that casts doubt on the purely orthographic account is that it assumes that once a person learns to read, then the phonologically oriented lexical representations already existing for the purposes of production are totally supplanted by orthographic representations and production must take place via rule conversion from the orthography. It seems preferable to say that, instead of replacing the phonological lexical representations, knowledge of orthography only modifies these representations (as suggested by Ehri, 1980).

Whatever the explanation for the results of the two experiments (and there are undoubtedly explanations other than those given here), one thing that seems clear is that pronunciation is not directly represented in the lexical entries, to be "read out" when required. Instead, it seems that overt pronunciations, or instructions to the articulators that lead to overt pronunciations, are derived from more abstract representations that are morphemically structured.

The view put forward here-that there is a single $a b$ stract lexical representation that underlies both spelling and pronunciation has been opposed by Allport and Funnell (1981) on evidence from brain-damaged subjects. They discussed the disabilities of several patients who appeared to show a dissociation between orthographic and phonological lexical representations. Most of the patients discussed, however, had such a dissociation in their input mechanisms, implying that the visual input device and the auditory input device have separate pathways to the 
cognitive or semantic center of the lexicon. More relevant here is evidence for a dissociation in the production mechanisms, in which the spoken and written output devices are shown to emanate independently from the cognitive center. Allport and Funnell did refer to such evidence, in particular, to a patient described by Beauvois and Dérouesné (1981) who had impaired written production but intact oral production (as well as the ability to convert phonemes to graphemes, and to read correctly). This, however, does not necessarily preclude the existence of an abstract representation from which spelling and pronunciation are derived. It is possible that the patient had a dysfunction of the mechanisms deriving the spelling from the abstract representation, whereas the mechanism deriving pronunciation from the abstract representation remained intact.

Of course, much of the interpretation of the experiments reported here is highly speculative, and further empirical research is needed to sharpen the ideas. However, what is clear is that models that are constructed to describe the lexical-access system will need to account for the difficulty that subjects experience in recognizing the homophony of pairs of words whose morphemic structures differ, and also they will need to explain why this difficulty markedly diminishes when the words are spoken aloud.

\section{REFERENCES}

Allport, D. A., \& Funnell, E. (1981). Components of the mental lexicon. Philosophical Transactions of the Royal Society of London, $B, 295,397-410$.

Benuvois, M. F., \& Dénouesné, J. (1981). Lexical and orthographic agraphia. Brain, 104, $21-49$.

Carroll, J. B., Davies, P., \& Richman, B. (1971). The American Heritage word frequency book. Boston: Houghton-Mifflin.

Chom8ky, C. (1973). Reading, writing and phonology. In F. Smith (Ed,), Psycholinguistics and reading. N.Y: Holt, Rhinehart \& Winston.

Chomsky, N., \& Halle, M. (1968). The sound pattern of English. N.Y: Harper \& Row.

Ehri, L. C. (1980). Reading and spelling in beginners: The development of orthographic images as word symbols in lexical memory. In V. Frith (Ed.), Cognitive processes in spelling. London: Academic press.

Ehri, L. C., \& Wilce, L. S. (1980). The influence of orthography on reader's conceptualization of the phonemic structure of words. Applied Psycholinguistics, 2, 371-385.

Groson, E. J., \& Guinet, L. (1971). Perception of inflections in brief visual presentation of words. Journal of Verbal Learning and Verbal Behavior, 10, 182-189.

Henderson, L. (1982). Orthography and word recognition in reading. London: Academic Press.

JARvelLA, R. J., \& Meijers, G. (1983). Recognizing morphemes in spoken words: Some evidence for a stem organized mental lexicon. In G. B Flores d'Arcais \& R. J. Jarvella (Eds.), The process of language understanding. N.Y: Wiley.

KEREx, A. (1976). The phonological relevance of spelling pronunciation. Visible Language, 10, 323-338.

Monton, J. (1980). The logogen model and orthographic structure. In U. Frith (Ed.), Cognitive processes in spelling. London: Academic Press.

Rubengtein, H. (1974). Psycholinguistics: An overview. In T. A.
Sebeok (Ed.), Current trends in linguistics (Vol. 12). The Hague: Mouton.

Seidenberg, M. S., \& Tanenhaus, M. K. (1979). Orthographic effects on rhyme monitoring. Journal of Experimental Psychology: Human Learning and Memory, 5, 546-554.

Stanners, R. F., Neiser, J. J., Hernon, W. P., \& Hall, R. (1979). Memory representation for morphologically related words. Journal of Verbal Learning and Verbal Behavior, 118, 399-412.

TAFT, M. (1979). Recognition of affixed words and the word frequency effect. Memory \& Cognition, 7, 263-272.

TAFT, M. (1982). An alternative to grapheme-phoneme conversion rules? Memory \& Cognition, 10, 465-474.

TAFT, M., \& Forster, K. I. (1975). Lexical storage and retrieval of prefixed words. Journal of Verbal Learning and Verbal Behavior, 14, 638-647.

\section{NOTES}

1. The symbol \# is adopted here, following $\mathrm{N}$. Chomsky and Halle (1968), to represent a word boundary.

2. Even though $/ \mathbf{r} /$ is not pronounced in the word PATTER in Australian dialect, it is included in the underlying representation because it comes to the surface in PATTERING.

\section{APPENDIX}

The Items Used in Experiments 1 and 2, the Words With Which the Items are Homophonic, and the Percentage of Subjects Who Detected the Homophony of the Words in Both Experiments

\begin{tabular}{cccc} 
Item & $\begin{array}{c}\text { Homophonic } \\
\text { Pair }\end{array}$ & $\begin{array}{c}\text { Experi- } \\
\text { ment 1 }\end{array}$ & $\begin{array}{c}\text { Experi- } \\
\text { ment 2 }\end{array}$ \\
\hline
\end{tabular}

Condition 1

(different morphological structure; inflected item)

$\begin{array}{llrr}\text { Billed } & \text { Build } & 20 & 70 \\ \text { Goaled } & \text { Gold } & 10 & 70 \\ \text { Fined } & \text { Find } & 50 & 90 \\ \text { Pattered } & \text { Patted } & 10 & 80 \\ \text { Blazers } & \text { Blazes } & 10 & 70 \\ \text { Brews } & \text { Bruise } & 50 & 90 \\ \text { Cowered } & \text { Coward } & 30 & 80 \\ \text { Frees } & \text { Freeze } & 80 & 100 \\ \text { Humoured } & \text { Humid } & 0 & 40 \\ \text { Matted } & \text { Mattered } & 20 & 80 \\ \text { Paced } & \text { Paste } & 20 & 60 \\ \text { Sighs } & \text { Size } & 50 & 70 \\ \text { Stretchers } & \text { Stretches } & 0 & 80 \\ \text { Tortures } & \text { Torches } & 30 & 50 \\ \text { Whirled } & \text { World } & 20 & 100 \\ \text { Whacks } & \text { Wax } & 50 & 90\end{array}$

Condition 2

(different morphological structure; uninflected item)

$\begin{array}{lllr}\text { Ode } & \text { Owed } & 20 & 50 \\ \text { Staid } & \text { Stayed } & 70 & 90 \\ \text { Suede } & \text { Swayed } & 30 & 60 \\ \text { Lynx } & \text { Links } & 90 & 100 \\ \text { Lax } & \text { Lacks } & 60 & 70 \\ \text { Guise } & \text { Guys } & 50 & 80 \\ \text { Mist } & \text { Missed } & 90 & 100 \\ \text { Seize } & \text { Sees } & 70 & 70 \\ \text { Clause } & \text { Claws } & 70 & 90 \\ \text { Hire } & \text { Higher } & 50 & 90 \\ \text { Tide } & \text { Tied } & 50 & 100\end{array}$




\begin{tabular}{llcr}
\multicolumn{4}{c}{ APPENDIX (continued) } \\
\cline { 1 - 2 } Item & $\begin{array}{c}\text { Homophonic } \\
\text { Pair }\end{array}$ & $\begin{array}{c}\text { Experi- } \\
\text { ment 1 }\end{array}$ & $\begin{array}{c}\text { Experi- } \\
\text { ment 2 }\end{array}$ \\
\hline Duct & & & \\
Pact & Ducked & 40 & 90 \\
Bard & Packed & 80 & 90 \\
Wade & Barred & 20 & 60 \\
Baste & Weighed & 50 & 80 \\
& Based & 20 & 50 \\
\multicolumn{1}{c}{ (same } & morphological structure; inflected item) \\
Cited & Sighted & 100 & 80 \\
Waived & Waved & 100 & 90 \\
Buries & Berries & 70 & 90 \\
Dyed & Died & 90 & 100 \\
Flees & Fleas & 90 & 90 \\
Heeled & Healed & 60 & 80 \\
Guerrillas & Gorillas & 80 & 70 \\
Floured & Flowered & 70 & 80 \\
Lutes & Loots & 90 & 60 \\
Peddled & Pedalled & 40 & 30 \\
Reigned & Rained & 90 & 100 \\
Peaked & Peeked & 50 & 60 \\
Whines & Wines & 100 & 100 \\
Yokes & Yolks & 60 & 70 \\
Rapped & Wrapped & 60 & 90 \\
Manors & Manners & 100 & 100 \\
& & &
\end{tabular}

\begin{tabular}{lllr}
\multicolumn{4}{c}{ APPENDIX (continued) } \\
\hline Item & $\begin{array}{c}\text { Homophonic } \\
\text { Pair }\end{array}$ & $\begin{array}{c}\text { Experi- } \\
\text { ment 1 }\end{array}$ & $\begin{array}{r}\text { Experi- } \\
\text { ment 2 }\end{array}$ \\
\hline \multicolumn{3}{c}{ Condition 4 } \\
Carat & morphological structure; & \\
Feat & Carrot & 100 & 100 \\
Meddle & Feet & 100 & 100 \\
Flair & Medal & 20 & 60 \\
Sleigh & Flare & 60 & 50 \\
Storey & Slay & 100 & 100 \\
Clime & Story & 100 & 100 \\
Maize & Climb & 100 & 100 \\
Blew & Maze & 100 & 100 \\
Raze & Blue & 100 & 100 \\
Flaw & Raise & 80 & 100 \\
Gambol & Floor & 80 & 100 \\
Stake & Gamble & 100 & 80 \\
Wring & Steak & 100 & 100 \\
Urn & Ring & 100 & 100 \\
Knead & Earn & 70 & 80 \\
\hline
\end{tabular}

(Manuscript received June 1, 1983;

revision accepted for publication October 28,1983 .)

\section{ERRATUM}

Becklen, R., and Cervone, D. (1983). Selective looking and the noticing of unexpected events. (Memory \& Cognition, 11(6), 601-608.-On page 605, in the paragraph in progress near the top of column 2, the group designations provided with the statistics are incorrect. The complete sentence in question should read: "However, if noticers and nonnoticers are compared within each treatment group separately, adequate justification is found for increasing power by combining the groups into FULL and PARTIAL conditions, as was done with the noticing-rate data [noticers vs. nonnoticers, Group T: $\mathrm{t}(21)=.60$, n.s.; Group E: $\mathrm{t}(19)=.94$, n.s.; Group $\mathrm{K}: \mathrm{z}=2.12, \mathrm{p}<.02^{2}$; Group KI: $\mathrm{t}(18)=$ $2.41, \mathrm{p}<.03] . "$ 